\title{
A ATUAÇÃO DAS COOPERATIVAS AGROPECUÁRIAS NA SUCESSÃO GERACIONAL NA REGIÃO DO COREDE NORTE (RS)
}

\author{
Zenicléia Angelita Deggerone ${ }^{1}$ \\ Carlos Alberto Oliveira de Oliveira²
}

\section{RESUMO}

Este trabalho se dedica a compreender de que modo as organizações cooperativas participam da sucessão geracional em propriedades rurais familiares, localizadas na região do Conselho Regional de Desenvolvimento Norte (Corede Norte), no Rio Grande do Sul. Para atender ao objetivo proposto, a pesquisa apresenta uma abordagem metodológica do tipo exploratória e descritiva, que utilizou métodos quantitativos e qualitativos para a coleta das informações em 11 cooperativas agropecuárias. Os resultados da pesquisa revelam que a saída dos jovens do campo é motivada, segundo os gestores das cooperativas, pela falta de diálogo na família, o que tem causado disputas em torno da tomada de decisão nas propriedades rurais. $\mathrm{E}$, para tentar reverter essa condição, os dirigentes apontam a necessidade de desenvolver ações propositivas de empoderamento dos/as jovens na participação das decisões junto às unidades de produção. Com base nesses resultados, o papel das organizações cooperativas seria desenvolver ações multidisciplinares que envolvam a família na discussão do gerenciamento e sucessão geracional do estabelecimento produtivo, com o propósito de estimular a permanência dos jovens no meio rural.

Palavras-chave: agricultura familiar, cooperativas, jovens, sucessão geracional.

\section{THE ACTUATION OF AGRICULTURAL COOPERATIVES IN THE GENERATIONAL SUCCESSION IN THE NORTH COREDE REGION OF (RS)}

\begin{abstract}
This work is dedicated to understanding how cooperative organizations participate of generational succession in family farms, located in the region of the North Regional Development Council (Corede North), in Rio Grande do Sul. In order to meet the proposed objective, the research presents a descriptive and exploratory methodological approach, and uses quantitative and qualitative techniques to collect information, which was carried out in 11 agricultural cooperatives. The results of the research shows that the exit of young people from the countryside is motivated, according to the managers of the cooperatives, by the lack of dialogue in the family,
\end{abstract}

\footnotetext{
${ }^{1}$ Graduada em Administração (UERGS). Mestrado em Ambiente e Desenvolvimento (UNIVATES). Doutoranda em Desenvolvimento Rural (UFRGS). Professora do Curso de Administração e Gestão Ambiental da Universidade Estadual do Rio Grande do Sul (UERGS). E-mail: zenicleiadeggerone@gmail.com

${ }^{2}$ Graduado em Agronomia (UFRGS). Mestrado em Agronegócios (UFRGS). Doutorando em Administração (UFRGS). Professor da Faculdade de Tecnologia do Cooperativismo (ESCOOP). E-mail: carlos.oliveira.agri@gmail.com
} 
which has caused disputes around the decision making in the rural properties. And to try to reverse this condition, the leaders point out the need to develop propositional actions to empower young people in the participation of decisions with the production units. Based on these results, the role of cooperative organizations would be to develop multidisciplinary actions involving the family in the discussion of the management and succession of the productive establishment, with the purpose of encourage the permanence of young people in rural areas.

Keywords: cooperatives, family farms, generational succession, young.

\section{INTRODUÇÃO}

O cooperativismo se constitui como meio de inclusão social e econômico, pois contribui para o desenvolvimento de agricultores familiares que cooperam por meio de organizações que atuam no segmento rural e agroindustrial.

As organizações cooperativas, segundo Schimidt e Perius (2002), são associações autônomas de pessoas que se unem voluntariamente e constituem uma empresa de propriedade comum para satisfazer aspirações econômicas, sociais e culturais. Esse tipo de organização baseia-se em valores de ajuda mútua, solidariedade, democracia, participação e autonomia.

Com base no princípio cooperativista de ajuda mútua, essas instituições possibilitam aos agricultores associados a agregação de valor aos produtos cultivados nas propriedades rurais e sua inserção no mercado, por meio da possibilidade de armazenamento e comercialização da produção agroindustrial.

Nesse contexto, tendo em vista a proximidade com os agricultores associados, as cooperativas agropecuárias promovem, no meio econômico, o fornecimento de assistência técnica, o aperfeiçoamento produtivo e tecnológico, a formação e a informação. Em termos sociais, sua atuação é semelhante a uma "extensão da propriedade do associado", se fazendo presente de forma constante nas unidades produtivas e gerando mecanismos influentes na identidade cultural dos agricultores familiares, em suas relações interpessoais e na difusão de conhecimento técnico e tecnológico no meio rural (SPANEVELLO; LAGO, 2007).

Com a atuação das cooperativas no meio rural, a agricultura familiar veio se consolidando no cenário produtivo de alimentos e no fornecimento de matérias-primas para o desenvolvimento rural brasileiro (SCHNEIDER, 2001). Isso foi possível devido à multifuncionalidade que essa categoria representa para a reprodução socioeconômica das unidades familiares de produção, além de promover a segurança alimentar das famílias presentes no meio rural e de contribuir com a produção de alimentos para a sociedade brasileira. Da mesma forma, ela promove a continuidade do tecido social e cultural das comunidades e auxilia na conservação dos recursos naturais e na manutenção das paisagens rurais (CARNEIRO; MALUFF, 2003).

Essa forma de organização social e de produção econômica tem, no entanto, encontrado dificuldades para se reproduzir socialmente, porém, algumas pesquisas (CARNEIRO,1998; BRUMER, 2001; SCHMITZ, 2007; CASTRO, 2009; MENASCHE; DEGGERONE, LAROQUE E BARDEN, 2014) comprovam que as perspectivas de concretização do processo sucessório ou da permanência de um dos filhos na gestão da propriedade, no lugar de seus pais, na condição de agricultor, se amplia diante de fatores estimuladores, tais como políticas públicas e formação, além do acompanhamento realizado por organizações sindicais e por instituições de fomento técnico e de extensão rural. 
Diante do trabalho realizado, também verifica-se que as cooperativas agropecuárias têm inserção na organização das atividades produtivas desenvolvidas nas propriedades rurais, e, por isso, vislumbra-se que a continuidade das atividades agropecuárias e a permanência da juventude rural ${ }^{3}$ constituem os principais fatores que fundamentam a própria existência das cooperativas. Com a saída dos jovens do meio rural, fica a indecisão a respeito de como se dará a renovação das gerações de agricultores no campo e no quadro social das cooperativas agropecuárias.

Com base nessas questões, o objetivo geral deste trabalho consiste em compreender de que modo as organizações cooperativas participam da sucessão geracional em propriedades rurais familiares localizadas na região do Conselho Regional de Desenvolvimento Norte (Corede Norte) do estado do Rio Grande do Sul. Especificamente, pretendeu-se, com este trabalho: a) identificar, no Corede Norte, quais as cooperativas de ramo agropecuário que atuam junto à agricultura familiar; b) caracterizar as ações que as cooperativas agropecuárias desenvolvem junto aos associados, voltadas à sucessão geracional; e c) identificar as ações que podem ser implementadas pelas cooperativas para estimular a sucessão geracional nas propriedades rurais.

\section{FUNDAMENTAÇÃO TEÓRICA}

Nesta seção, são apresentadas algumas discussões acerca da importância do cooperativismo para a organização social e econômica da agricultura familiar. Além disso, também são debatidos os temas recorrentes à problemática dos jovens no meio rural a partir de questões que podem levar à sua migração e os condicionantes que contribuem para que aconteça o processo sucessório de jovens em atividades rurais.

\subsection{COOPERATIVAS AGROPECUÁRIAS: A IMPORTÂNCIA ECONÔMICA E SOCIAL PARA OS AGRICULTORES FAMILIARES}

A prática da cooperação é um dos mecanismos capazes de permitir à sociedade, uma vez organizada em empreendimentos cooperativistas, a inserção em um mercado globalizado. Esse fator aumenta as chances de agregar valor aos resultados do trabalho, além de garantir a comercialização dos produtos e, consequentemente, possibilitar que os indivíduos melhorem suas condições socioeconômicas.

A partir dessa definição, Rech (2000) destaca que as cooperativas têm uma dupla natureza, uma social e outra econômica, e, nessa relação, elas são administradas e controladas pela comunidade para atender aos associados em serviços que não conseguem realizar individualmente.

Nessa direção, Chayanov (2017) afirma que as cooperativas são uma das instituições que possibilitam aos agricultores acessar os mercados globalizados e promover a socialização do trabalho. Para o autor, o cooperativismo permite aos cooperados assumirem o controle das etapas de processamento e comercialização de seus produtos agrícolas no lugar de grandes empresas.

Nesse sentido, verifica-se que, além de conciliar os desafios da globalização dos mercados, exigindo uma gestão estratégica enquanto entidade cooperativa, as instituições cooperativas devem primar pelo desenvolvimento econômico e social de seus associados, pois, conforme destaca Abreu (2004), o agricultor associado é

\footnotetext{
${ }^{3}$ Neste trabalho, utiliza-se a definição de juventude rural conceituada por Weisheimer (2007). O autor considera que a juventude é uma construção social, cultural e histórica, sobre a qual se impõem diferentes mecanismos de integração social (WEISHEIMER, 2007, p. 238).
} 
proprietário do empreendimento, provedor das reservas destinadas à mutua utilização e usuário dos produtos e serviços oferecidos pela cooperativa.

Bialoskorski Neto (2001) explica que, em regiões onde há grande número de agricultores associados em cooperativas agropecuárias, o nível da renda agrícola é maior e o desenvolvimento da agricultura é mais proeminente. A partir desse mesmo enfoque, Alves (2003) ressalta que as cooperativas podem gerar maiores oportunidades de trabalho, fortalecendo as instituições democráticas, além de promover a humanização das relações econômicas e a diminuição de desigualdade de renda.

Além de trazer vantagens econômicas, Silva et al. (2006) consideram que o uso coletivo de recursos por parte dos membros da cooperativa pode aumentar o padrão tecnológico e que a existência do grupo facilita a obtenção de recursos e a diversificação de atividades, o que pode significar emprego e aumento da renda familiar. Além disso, o esforço coletivo no desenvolvimento de projetos pode criar um espaço de permanência e perspectivas para as gerações mais novas.

Outra vantagem propiciada pelo cooperativismo é a prática de capacitação pessoal e profissional oferecida aos cooperados. Por meio dos departamentos técnicos, as cooperativas atuam como multiplicadoras de conhecimentos, com a disseminação de informações fundamentais para o desempenho de suas atividades em todos os ramos, mas especialmente no cooperativismo agropecuário (LIMBERGER, 1996).

Dessa forma, partindo da perspectiva do cooperativismo como promotor de melhores condições de vida para seus associados, pode-se atribuir a ele um importante aporte (embora não exclusivo) no processo sucessório dos estabelecimentos familiares cooperativamente atuantes: quanto maior a capacidade da cooperativa de atender às necessidades dos sucessores enquanto agricultores e jovens agricultores familiares, maior a possibilidade de concretização da sucessão geracional (SPANEVELLO; LAGO, 2007) e maior a vida útil da cooperativa, pois as organizações também necessitam de sucessores para continuarem ativas no meio rural.

\subsection{INTERFACE ENTRE COOPERATIVISMO E SUCESSÃO GERACIONAL}

Uma das características da agricultura familiar está diretamente relacionada com sua reprodução social ao longo do tempo, por meio do processo de transferência do controle e da gestão ou da sucessão familiar (GASSON; ERRINGTON, 1993), em que se dá por meio da colocação de um dos filhos no lugar dos pais obedecendo a uma organização interna demarcada pela autoridade paterna.

Nessa perspectiva, Spanevello et al. (2014) argumentam que, no passado, a sucessão familiar não enfrentava problemas para a instalação de novas gerações de agricultores. Nesse tempo, sequer se cogitava a ausência de sucessores entre as famílias. Ou seja, havia interesse dos filhos em tornarem-se agricultores, e os pais apoiavam esse processo naturalmente.

Porém, a partir de 1960, esse modelo sucessório vigente até então começa a entrar em crise. De acordo com Abramovay et al. (1998), até esse período, a agricultura familiar produzia uma nova geração de agricultores com base no critério de que filho de agricultor também seria agricultor.

Essas crises são decorrentes das transformações que passaram a ocorrer no meio rural, como mostram Silvestro et al. (2001), Mello et al. (2003), Spanevello (2008) e Castro (2009). Segundo esses autores, as mudanças estruturais na sociedade em geral, desde a questão da renda, da penosidade do trabalho agrícola, da desvalorização da ocupação, da falta de lazer no meio rural, da autonomia na 
gestão da propriedade e do desejo de querer viver em um lugar melhor, geram implicações na sucessão das propriedades rurais.

Outro fator que também culmina na saída do jovem do meio rural está relacionado ao processo histórico de desigualdade de gênero, em um contexto no qual as mulheres não participavam do transcurso de sucessão e não tinham espaço de participação (STROPASOLAS, 2004).

De acordo com Carneiro (2001), o trabalho exercido pelas mulheres é tradicionalmente visualizado apenas como uma extensão do papel de esposa, não sendo, portanto, estas, reconhecidas socialmente como gestoras da propriedade familiar e "merecedoras" de herança. Diante disso, na divisão do patrimônio, uma das regras costumeiras é recompensar as mulheres com o enxoval composto de roupas de cama, mesa e banho, utensílios domésticos, máquina de costura e animais domésticos (bovinos de leite), podendo ter mais ou menos itens de acordo com as condições financeiras dos pais.

Esses e outros elementos colaboraram para que muitas propriedades fossem abandonadas devido à falta de interesse dos filhos em permanecer na atividade rural. Outras acabaram se tornando sítios de lazer, e outras, ainda, serão incorporadas por propriedades maiores ou por trabalhadores liberais. Entretanto, qualquer um dos possíveis destinos coloca em risco a reprodução da agricultura familiar.

Outros estudos têm comprovado que esse cenário de imprecisão sobre a sucessão geracional pode ser amenizado diante de fatores considerados estimuladores para os jovens rurais. Para Deggerone, Laroque e Barden (2014), na região Norte do estado do Rio Grande do Sul, a permanência dos jovens tem forte relação com o diálogo familiar entre as gerações, somado a uma formação educacional que enfatize e discuta o rural, o acesso ao lazer e à comunicação, além da remuneração do trabalho dos jovens, aliada a políticas públicas inclusivas que contribuam para a permanência destes nas unidades produtivas familiares.

O trabalho realizado por Brumer (2001) apresenta que a permanência do jovem no meio rural acontece quando a família considera que os filhos precisam de autonomia para conduzir algumas atividades produtivas nas propriedades rurais, além de serem remunerados pelo trabalho executado e pela ampliação dos espaços sociais para a atuação dos jovens.

Menasche e Schmitz (2007) consideram que os jovens almejam a continuidade dos projetos de vida dos seus pais e avós, pois existe uma relação moral, relacionada à reprodução simbólica da família e de sua ancestralidade, bem como entendem que o espaço rural é um bom ambiente para se viver.

Os estudos existentes apontam para a impossibilidade de um único fator casual ou explicativo para a permanência do jovem no meio rural e, diante disso, é importante referendar a importância do papel das cooperativas agropecuárias junto às propriedades rurais e aos jovens agricultores familiares.

Dessa forma, as organizações têm papel relevante como agentes de desenvolvimento econômico e social (PUTMAN, 1996, BUARQUE, 1998), a partir da inclusão dos sujeitos (jovens agricultores familiares), empreendendo relações de participação, cooperação e interação social, que, em última análise, devem capacitar e potencializar as especificidades locais para melhorar as condições de vida das famílias dos agricultores familiares.

Com base nessas reflexões, infere-se que as cooperativas poderiam contribuir com a mobilização social e com a capilaridade para fomentar a permanência dos jovens em atividades produtivas rurais, devido à capacidade de ligação e ao envolvimento das instituições com os agricultores familiares. Assim, por meio dessa inferência, os dados apresentados na próxima seção pretendem demostrar de que 
modo as cooperativas da agricultura familiar localizadas no Corede Norte estão fomentando a permanência dos jovens no meio rural.

\section{MÉTODO}

O procedimento metodológico utilizado neste trabalho consiste em uma abordagem descritiva e exploratória. Com base nos objetivos propostos para este trabalho, o modo de investigação escolhido para a sua execução foi o estudo de casos múltiplos, que buscou verificar como as organizações cooperativas contribuem para a sucessão geracional da agricultura familiar na região do Corede $\mathrm{Norte}^{4}$, no estado do Rio Grande do Sul.

Para a coleta das informações, foram utilizados métodos quantitativos e qualitativos em 11 cooperativas ${ }^{5}$ agropecuárias que têm em seu quadro social somente agricultores familiares, conforme caracterização dada pela Lei 11.326/2006 ${ }^{6}$. Essas cooperativas operam predominantemente na comercialização da produção de seus associados para mercados privados e institucionais públicos.

Nas cooperativas pesquisadas, foi realizada a coleta de dados, por meio de entrevistas com os coordenadores e dirigentes das respectivas instituições, entre os meses de abril a julho de 2016.

Após o levantamento das informações, realizou-se a análise das entrevistas registradas nos questionários orientadores, por meio da análise de conteúdo. Uma parte dos dados gerados pelos questionários orientadores foi tabulada a partir de ferramentas de estatística descritiva, e para a compreensão quantitativa das informações, enquanto os demais dados são, neste trabalho, apresentadas de forma qualitativa.

\section{AS COOPERATIVAS DA AGRICULTURA FAMILIAR NO COREDE NORTE E SUA ATUAÇÃO COM OS JOVENS AGRICULTORES}

Na região do Alto Uruguai - Corede Norte, existem cerca de 18 cooperativas que atuam especificamente com o público de agricultores familiares, sendo que este estudo levantou informações de 11 cooperativas, conforme representação da Figura 1.

\footnotetext{
${ }^{4}$ O Conselho Regional de Desenvolvimento Norte (Corede Norte) é um dos 24 Conselhos Regionais de Desenvolvimento do Rio Grande do Sul. Tem uma população total de 218.176 habitantes (IBGE/2006) e uma área de $5.908,5 \mathrm{~km}^{2}$, com densidade populacional de 36,9 hab. $/ \mathrm{km}^{2}$. A cidade polo é Erechim, mas o Corede abrange também os municípios de Aratiba, Áurea, Barão de Cotegipe, Barra do Rio Azul, Benjamin Constant do Sul, Campinas do Sul, Carlos Gomes, Centenário, Charrua, Cruzaltense, Entre Rios do Sul, Erebango, Erval Grande, Estação, Faxinalzinho, Floriano Peixoto, Gaurama, Getúlio Vargas, Ipiranga do Sul, Itatiba do Sul, Jacutinga, Marcelino Ramos, Mariano Moro, Paulo Bento, Ponte Preta, Quatro Irmãos, São Valentim, Severiano de Almeida, Três Arroios e Viadutos.

${ }^{5}$ No Corede Norte, existem 18 cooperativas agropecuárias, mas este estudo pesquisou apenas 11, pois sete cooperativas não aceitaram participar da pesquisa.

${ }^{6}$ Considera-se agricultor familiar e empreendedor familiar rural aquele que pratica atividades no meio rural, atendendo, simultaneamente, aos seguintes requisitos: I - não detenha, a qualquer título, área maior do que 4 (quatro) módulos fiscais; II - utilize predominantemente mão-de-obra da própria família nas atividades econômicas do seu estabelecimento ou empreendimento; III - tenha percentual mínimo da renda familiar originada de atividades econômicas do seu estabelecimento ou empreendimento, na forma definida pelo Poder Executivo; IV - dirija seu estabelecimento ou empreendimento com sua família (BRASIL, 2006).
} 
Figura 1 - Localização das cooperativas englobadas na pesquisa, no Corede Norte.

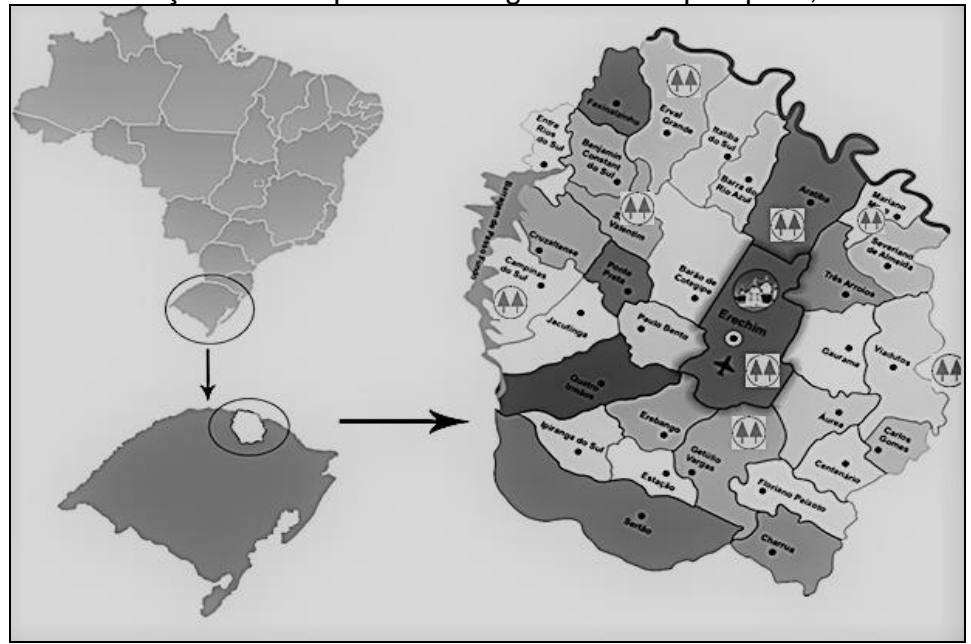

Fonte: Adaptação de Adau (2014)

As cooperativas pesquisadas atuam em diferentes segmentos produtivos, nos quais organizam e potencializam a comercialização de alimentos e matériasprimas no meio rural. Dessa forma, a produção e a comercialização de alimentos in natura é realizada por oito cooperativas e a venda de produtos provenientes de agroindústrias familiares - como massas, biscoitos, embutidos, doces e geleias - é efetuada por sete cooperativas, conforme demonstra a Figura 2. Nesses dois segmentos, a comercialização dos alimentos é realizada por meio dos mercados institucionais, identificados pelo Programa de Aquisição de Alimentos (PAA) ${ }^{7}$ e pelo Programa Nacional de Alimentação Escolar (PNAE) ${ }^{8}$, construídos a partir da atuação do Estado, por meio de políticas públicas voltadas para atender à agricultura familiar e para a segurança alimentar e nutricional das populações em situação de risco e vulnerabilidade social.

\footnotetext{
${ }^{7}$ O Programa de Aquisição de Alimentos (PAA) propicia a aquisição de alimentos de agricultores familiares a preços compatíveis aos praticados nos mercados regionais e promove a doação desses alimentos para entidades socioassistenciais (BRASIL, 2011).

8 O Programa Nacional de Alimentação Escolar (PNAE) oferece alimentação escolar e ações de educação alimentar e nutricional a estudantes de todas as etapas da educação básica pública. Do total dos recursos financeiros repassados pelo Governo Federal, no mínimo 30\% (trinta por cento) deverão ser utilizados na aquisição de gêneros alimentícios diretamente da agricultura familiar (BRASIL, 2009).
} 
Figura 2 - Segmentos produtivos nos quais as cooperativas atuam

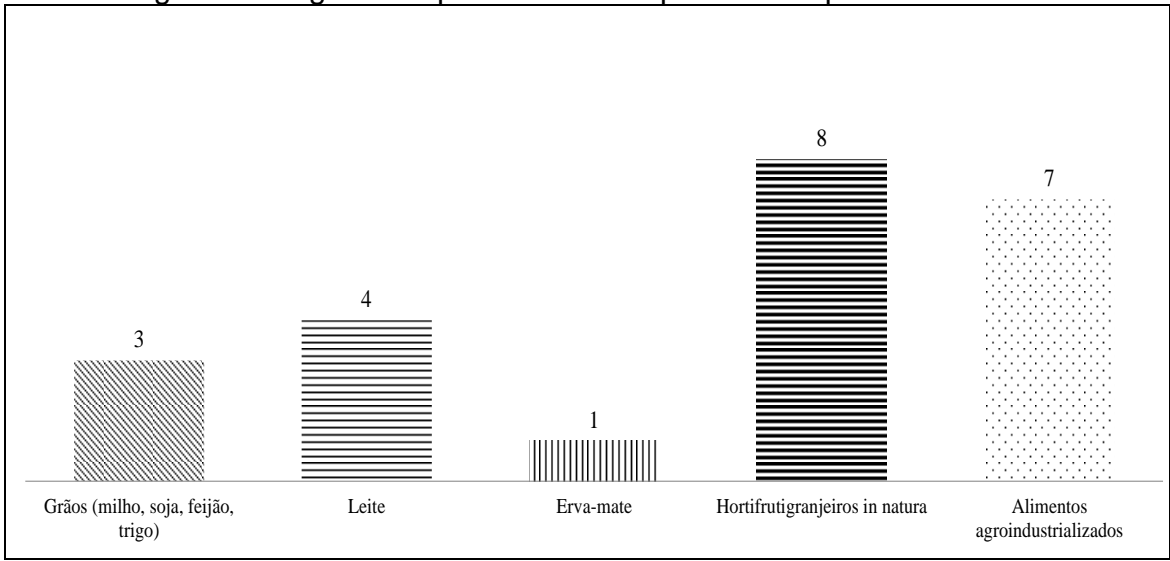

Fonte: Dados da pesquisa (2016)

Nesse tipo de comercialização, conforme Grisa e Porto (2015), em virtude de os alimentos serem produzidos e consumidos em locais relativamente próximos, os mercados institucionais operados pelas cooperativas da agricultura familiar têm fomentado a criação de circuitos curtos de comercialização, o que favorece a aproximação entre produtores e consumidores, a construção e o resgate de identidades e a valorização da cultura alimentar local/regional e do trabalho dos agricultores familiares.

Os resultados da pesquisa também identificam que o recolhimento, o resfriamento e a comercialização de leite fluido in natura são efetuados por quatro cooperativas, as quais destinam o produto para empresas do segmento lácteo. Três cooperativas atuam no fomento e na comercialização de grãos (feijão, milho e trigo), que são destinados para empresas do ramo alimentício. Já a comercialização do grão de soja é destinada a empresas que produzem biodiesel na região. Nesses dois segmentos produtivos, as cooperativas, por serem de pequeno porte, atuam como intermediadoras da compra e da comercialização do produto, sendo o beneficiamento realizado por outros agentes produtivos.

Segundo Limberger (1996), as cooperativas se constituíram como uma das alternativas para sublimar a ação dos comerciantes independentes e para atuar como intermediadoras na compra dos produtos dos agricultores e na destinação para as indústrias compradoras, visando pagar um preço mais favorável aos agricultores associados. Para Williamson (1981), as instituições cooperativistas permitem estreitar os elos de intermediação das transações no interior da cadeia produtiva, uma vez que funcionam como mediadoras na comercialização da produção, em especial aquelas voltadas ao ramo agropecuário.

Ainda em relação à pesquisa, apenas uma cooperativa atua na compra e no processamento de erva-mate de seus agricultores associados. A instituição é responsável por uma agroindústria que realiza o beneficiamento e a disposição final do produto.

Segundo Lauschner (1984), as cooperativas agroindustriais, ao disporem de uma agroindústria, oferecem oportunidades a montante e a jusante a seus associados, pois podem oferecer preços mais competitivos de mercado, de assistência técnica e creditícia, de planejamento da produção e na destinação dos produtos manufaturados. 
As cooperativas estudadas trabalham com diferentes segmentos produtivos, mas é importante destacar que algumas se constituíram a partir dos anos 1990 e outras surgiram em decorrência das políticas públicas do Governo Lula, a partir dos anos 2000. Essas instituições englobam um número total de 3.360 associados (Figura 3). Conforme estratificação, 2.868 associados são homens $(85,36 \%)$ e 492 são mulheres $(14,64 \%)$.

Essa informação demonstra que, no momento da associação da família à cooperativa, somente o nome do proprietário é exigido para fins de comprovação cadastral e como representante legal da propriedade rural.

Figura 3 - Estratificação do quadro social

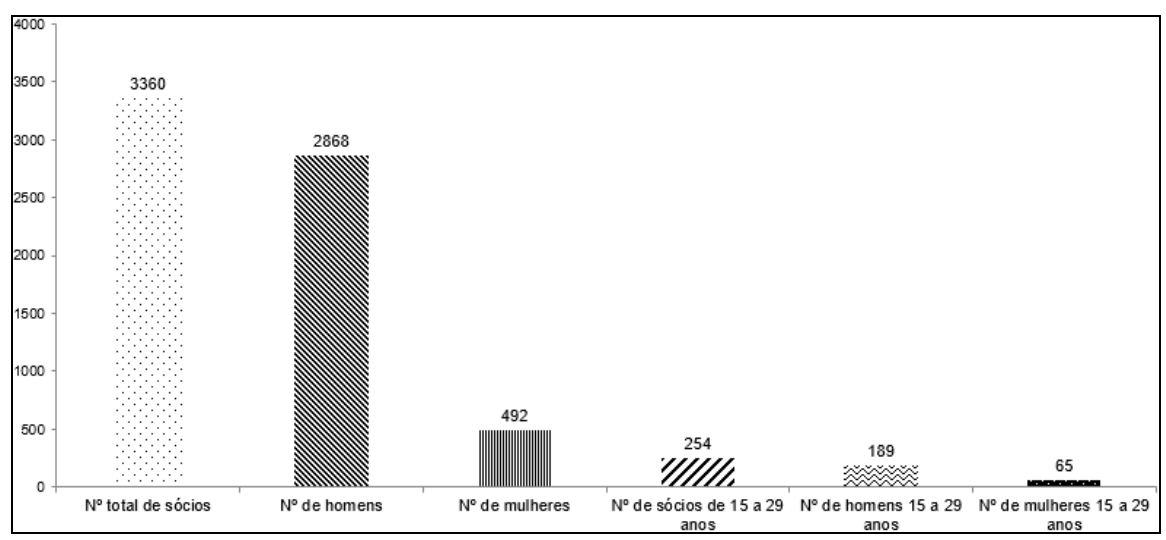

Fonte: Dados da pesquisa (2016)

Em relação à quantidade de jovens (idade entre 15 e 29 anos), também foi identificado um número reduzido de associados nessa faixa etária às organizações. Foi verificado um total de 254 jovens associados às cooperativas e, dentre esses, 189 são do sexo masculino e 65 são do sexo feminino.

A partir de uma análise geral, os dados permitem inferir que cabe ao homem a participação e a representação nos espaços de interação com a cooperativa, pois ainda existe certa invisibilidade acerca da importância da inclusão dos jovens e das mulheres na participação e na tomada de decisões.

Em relação à baixa participação feminina nessas instituições, além da afirmação apresentada no parágrafo anterior, as mulheres ainda são subjugadas em virtude dos modelos que foram construídos a partir de relações de poder. A exclusão das mulheres desse contexto foi e ainda é legitimada pela sociedade (família, igreja, Estado) de forma clarividente, a partir da dominação masculina (BOURDIEU, 1995). A partir dessa afirmação, a mulher não se visualiza como agente do processo de participar de decisões e intervir nas relações estabelecidas entre as propriedades rurais com as instituições.

Já em relação aos jovens, é evidenciada uma incipiente participação nas instituições cooperativistas, pois essa situação emerge ao encontro do que Woortmann e Woortmann (1997) constatam ao evidenciar que o homem adulto concentra, em suas mãos, o controle sobre a renda familiar e sobre a gestão da produção agrícola, estando também relacionado à inserção ou não dos jovens nas instituições. Isso se deve ao fato de ser o pai a autoridade máxima dentro do grupo 
doméstico e é ele que determina quem deve participar das atividades que envolvem a gestão e as decisões relativas às propriedades rurais.

Abordando a reduzida participação dos jovens junto às cooperativas agropecuárias, a pesquisa levanta outros elementos que implicam a saída dos jovens do meio rural, conforme apresentado na Figura 4.

Figura 4 - Problemáticas que implicam a saída do jovem do meio rural

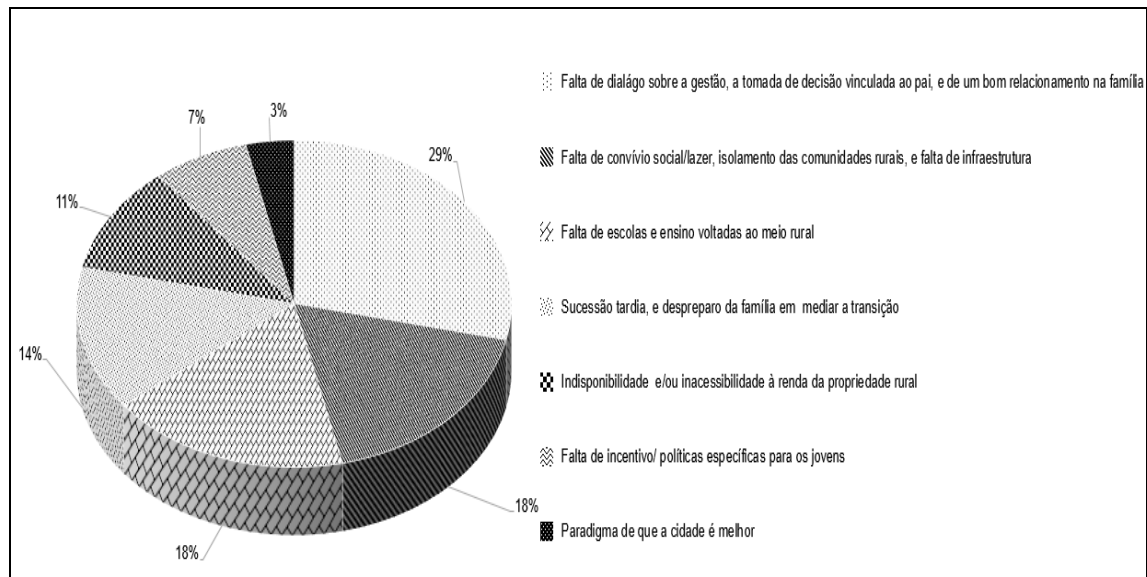

Fonte: Dados da pesquisa (2016)

Mediante as informações apresentadas, pode-se constatar que a baixa participação dos jovens nas instituições também está correlacionada com problemas recorrentes que têm contribuído com a sua saída do campo. Nesse caso, a pesquisa revela que, em $29 \%$ das respostas atribuídas pelos coordenadores das cooperativas, a falta de diálogo e de um bom relacionamento familiar tem causado disputas pela tomada de decisão e tem levado muitos jovens a migrar para os centros urbanos. $\mathrm{O}$ segundo elemento, com $18 \%$, está relacionado à falta de convívio social/lazer, ocasionado pelo distanciamento das comunidades rurais e pela falta de infraestrutura (internet, estradas de boa qualidade) para que os jovens tenham a oportunidade de se comunicar e diminuir "as distâncias" entre o rural e o urbano. Outro fator que implica a saída dos jovens está relacionado à falta de um ensino emancipatório (18\%) que permita aos alunos estudarem o rural e visualizarem boas oportunidades de renda, permanecendo nas propriedades rurais familiares. Como outra situação apontada (14\%) está a realização da sucessão tardia, devido ao despreparo da família em mediar a transição de modo que o jovem se integre paulatinamente ao processo de gestão e de tomada de decisões. Na visão dos coordenadores das cooperativas, a indisponibilidade e/ou inacessibilidade à renda da propriedade rural (11\%) também contribui para a saída dos jovens do meio rural. Além desses, outros elementos também foram citados com menor expressividade, como a falta de políticas públicas direcionadas aos jovens do meio rural e o persistente paradigma de que a cidade ainda é a melhor opção para morar e trabalhar.

Frente a esses dados, pode-se inferir que a baixa participação dos jovens nas cooperativas está relacionada à forma como a gestão é realizada nas propriedades rurais. Ou seja, os pais têm o poder decisório e os filhos têm poucas oportunidades de iniciar a condução das atividades produtivas, bem como a negociação e a participação desses em atividades e eventos oportunizados pelas 
instituições, o que, de certa forma, inviabiliza a presença do jovem e contribui para que ele busque seus espaços de inserção, visibilidade e autonomia em outros meios. Segundo o trabalho realizado por Bednaríková et al. (2016) com jovens na Russia, o reconhecimento do jovem enquanto sujeito do processo de gestão e organização da propriedade rural é identificado como um fator que diminui a probabilidade de migração dos jovens das áreas rurais.

Nessas situações, as cooperativas poderiam fazer cumprir sua função social ao ajudar os jovens e as famílias a enfrentarem esses problemas, o que consequentemente reverteria na maior participação de jovens e famílias nos quadros sociais das instituições. Porém, a pesquisa identifica que as cooperativas, por meio de suas estruturas organizacionais, têm concedido somente benefícios econômicos, a partir da garantia de compra dos produtos cultivados pelos agricultores associados, vinculada à garantia de preços justos.

$E$, nesse caso, a capilaridade existente entre as cooperativas e suas formas de inserção pode, então, ir além da relação econômico-comercial e oportunizar novas possibilidades de ações e projetos com cunho social. Nesse sentido, Frantz e Schonardie (2007) atribuem às cooperativas o papel de estar em constante comunicação e processo de educação com seus integrantes, por intermédio da qualificação de seus associados e dirigentes, e o de possibilitar que os associados participem política e economicamente dos projetos das cooperativas.

Assim, as atividades de interação social desenvolvidas pelas cooperativas com o objetivo de condicionar processos de sucessão geracional nas propriedades rurais familiares são apresentadas na Figura 5 . Os resultados revelam que três cooperativas incentivam a participação dos jovens junto aos conselhos fiscal e administrativo das instituições; duas cooperativas promovem atividades com diferentes temáticas, envolvendo viagens de fomento técnico, dias de campo e palestras; e apenas uma cooperativa desenvolve um projeto que busca incentivar os jovens a permanecer nas propriedades rurais. Além desses resultados, identifica-se também que cinco cooperativas não desenvolvem nenhuma ação de incentivo à permanência dos jovens no meio rural.

Figura 5 - Ações desenvolvidas pelas cooperativas voltadas à sucessão geracional

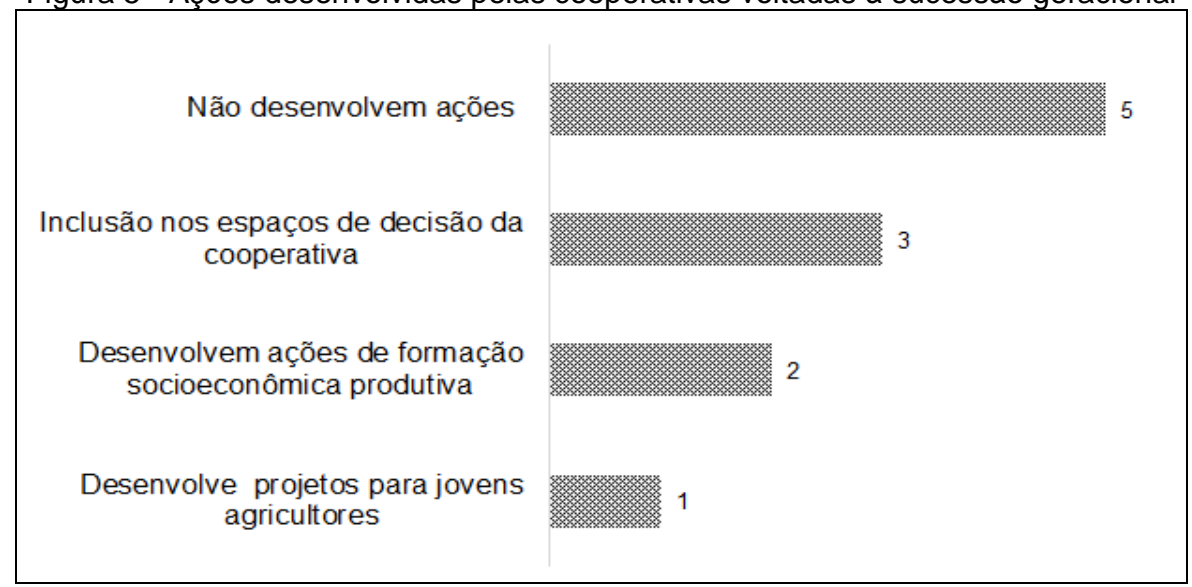

Fonte: Dados da pesquisa (2016) 
Em pesquisa realizada na região do Alto Jacuí, no Rio Grande do Sul, por Spanevello, Drebes e Lago (2011), verificou-se que os projetos desenvolvidos por cooperativas, muitas vezes não estão vinculados diretamente à sucessão geracional, mas eles podem exercer certa influência sobre as propriedades rurais e sobre os agricultores familiares cooperativistas e, por consequência, podem influenciar na decisão dos jovens em permanecer ou não no campo.

O único projeto identificado por essa pesquisa com o foco na permanência dos jovens no campo e em atividades agropecuárias envolve cerca de trinta jovens do sexo feminino e masculino, filhos dos agricultores associados à cooperativa, por meio de ações bimestrais, nas quais são trabalhados os temas de educação cooperativista, sucessão geracional, gênero, entretenimento, sustentabilidade, gestão e produção de leite nas propriedades rurais familiares.

A proposta desenvolvida por essa cooperativa vai ao encontro de uma perspectiva multidisciplinar que, além de proporcionar qualificação profissional e educação cooperativista, discute também as temáticas de sucessão geracional, gênero e entretenimento. Isso se justifica em razão de que, conforme referenciado por Deggerone, Laroque e Barden (2014), os processos de sucessão ocorrem quando existe diálogo familiar entre as gerações e acesso ao lazer e à comunicação, fatores que se tornam condições necessárias para a permanência dos jovens nas unidades produtivas familiares.

A ação dessa cooperativa, ao trabalhar com as temáticas sustentabilidade e gestão da produção, corrobora com a autonomia dos trabalhos junto à unidade de produção familiar (BRUMER, 2001), a partir do estímulo à diversificação das atividades produtivas e da apresentação de alternativas de produção, a partir da realidade da propriedade rural familiar.

Em relação às cooperativas que não desenvolvem nenhuma ação voltada à sucessão, em seus estudos, Silvestro et al. (2001) verificam que existe uma ausência das organizações representativas no apoio aos jovens rurais. E, conforme citam Spanevello, Drebes e Lago (2011), a falta de projetos específicos para os jovens pode ser atrelada à falta de recursos financeiros e de pessoal qualificado para desempenhar tais funções nas instituições cooperativistas.

A pesquisa também investiga quais as ações que as cooperativas poderiam organizar futuramente para contribuir com a permanência dos jovens no meio rural, uma vez que essas atividades também permitiriam que mais jovens pudessem participar das instituições cooperativas, representando a manutenção e a sobrevivência dessas no meio rural.

Assim, conforme evidencia a Figura 6, identifica-se que, em $31 \%$ das respostas dos dirigentes, as ações propositivas estariam voltadas a processos de empoderamento dos jovens nas tomadas de decisões junto às propriedades rurais. Em segundo lugar, com $27 \%$, os representantes comentaram a intenção de desenvolver programas de incentivo à diversificação da produção e o acesso a novos canais de comercialização, nesse caso, os jovens seriam os protagonistas e responsáveis pela execução e condução das atividades. Na terceira posição, com $15 \%$, as cooperativas avaliam que seja importante conceder assistência técnica para a produção e apoio à gestão das propriedades rurais. Na quarta colocação, com 12\%, as cooperativas pretendem desenvolver atividades de integração e valorização, por meio de encontros de jovens cooperativistas, viagens de intercâmbio, gincanas, jogos cooperativos e outros eventos que possam aproximar os jovens da cooperativa. $\mathrm{Na}$ quinta posição, com 11\%, aparece o desenvolvimento de projetos que condicionem a participação dos jovens na elaboração de ações e que incentivem a permanência no meio rural. Por último, as cooperativas ensejam promover o acesso dos jovens às 
políticas públicas existentes, por meio do Pronaf-Jovem, do PAA, do PNAE e de outras políticas e programas que possam ser utilizados pelos jovens agricultores familiares.

Figura 6 - Incentivos que as cooperativas poderiam conceder para a permanência dos jovens

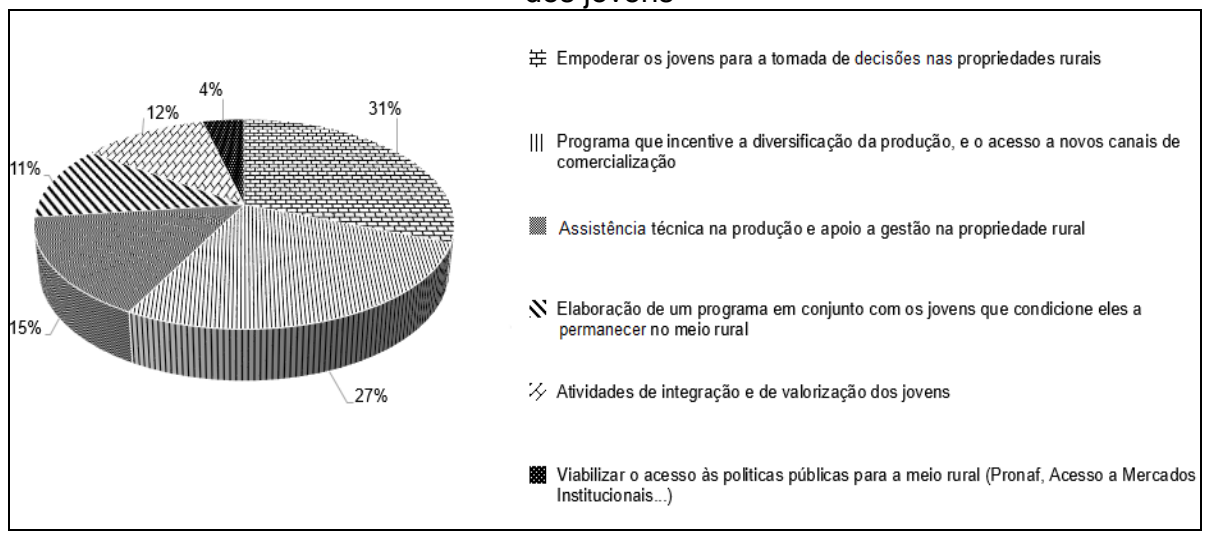

Fonte: Dados da pesquisa (2016)

A partir da exposição desses dados, verifica-se que ainda é visível a desatenção das cooperativas em assumir ações que promovam a sucessão geracional, com base em ações multidisciplinares que envolvam a família na discussão do gerenciamento e da sucessão geracional do estabelecimento produtivo, aliada a questões de gênero, entretenimento, renda e trabalho nas propriedades rurais. As ações ainda são idealizadas de modo singular e não interagem com um dos principais problemas que culminam na saída do jovem das propriedades rurais, relacionado à falta de diálogo e/ou de um bom relacionamento familiar, o que tem causado disputas pela tomada de decisão nas propriedades rurais.

Em estudo realizado no Mato Grosso do Sul, Morais, Binotto e Borges (2017) comprovam que a família tem papel preponderante para incentivar os jovens a permanecer no meio rural e a atuar conjuntamente na gestão do estabelecimento produtivo. Além disso, em trabalho realizado na Rússia, Bednaríková, Bavorová e Ponkina (2016) concluem que o apoio e o incentivo dos pais para que os jovens conduzam as atividades produtivas nas propriedades rurais está associado a uma menor probabilidade de esses jovens abandonarem as áreas rurais. Além disso, esses mesmos autores enfatizam que o desenvolvimento de cursos com foco na área agrícola permite que o jovem vislumbre o meio rural como uma boa oportunidade de trabalho e renda.

Dessa forma, comprovando as afirmações apresentadas acima, um estudo bibliográfico realizado por Gris et al. (2017), identificou que o incentivo dos familiares e a participação em atividades promovidas pelas cooperativas são fatores positivos que motivam a permanência dos jovens no meio rural. Por essa razão, confirma-se que uma das estratégias que poderia ser usada para promover a permanência de jovens no campo, seria por meio das cooperativas. Pois, ao investirem em educação, formação e informação dos cooperados, haveria prospecção para favorecer o crescimento e o desenvolvimento tanto da instituição quanto de seus cooperados, pois é papel da cooperativa orientar no sentido da constituição de valores humanos universais e gerar mecanismos capazes de atuar sobre a identidade cultural e sobre a inserção social de seus cooperados (SCHNEIDER, 1994). Pelo lado das instituições 
cooperativas, Griset al. (2017), mencionam que estas ao se envolverem com os jovens, colaboram para o surgimento de empreendedores rurais e também na captação de novos cooperados.

Nessa mesma perspectiva, Schneider (2001) considera que a razão de ser das cooperativas é a de melhorar a situação econômica, social e cultural de seus associados. Atribui como prioridade, também, a atuação dos jovens nas direções das cooperativas e destaca a importância de as ações das cooperativas envolverem a família, buscando que homens e mulheres sejam parceiros nos compromissos, nas responsabilidades e nos benefícios adquiridos na propriedade rural, por meio das cooperativas.

\section{CONSIDERAÇÕES FINAIS}

A realização deste estudo permitiu identificar que as cooperativas da agricultura familiar atuam em diferentes segmentos produtivos e operam predominantemente na comercialização da produção de seus associados para mercados privados e institucionais públicos. Nessa situação, a principal contribuição das cooperativas é sua atuação como intermediadora na compra dos produtos dos agricultores e na destinação às indústrias compradoras, favorecendo a redução do oportunismo dos atravessadores.

Contudo, apesar da atuação proeminente das cooperativas, verifica-se um baixo número de mulheres e jovens associados a essas instituições. Esse resultado é decorrente da inserção da figura paterna, a qual assume a representação da família e da propriedade rural, nos espaços de interação com a cooperativa, pois ainda existe certa invisibilidade da importância da inclusão dos jovens e das mulheres na participação e na tomada de decisões.

Essa situação é ampliada e justificada pela forma como a gestão é realizada nas propriedades rurais, em um contexto no qual o poder decisório é competência exclusiva do pai, que, de modo geral, não delega aos filhos a oportunidade de iniciar a condução das atividades produtivas. Além disso, também não Ihes possibilita a inserção na negociação e na participação em atividades e eventos oportunizados pelas instituições, o que, de certa forma, retira o jovem e faz com que ele assevere a necessidade de buscar espaços de inserção, visibilidade e autonomia em outros meios, no qual se inclui o urbano.

A respeito das ações organizadas pelas instituições cooperativas para que seja promovida a permanência dos jovens no meio rural, verifica-se que essas ações estão correlacionadas à participação dos jovens junto aos conselhos fiscal e administrativo das instituições, viagens de fomento técnico, dias de campo e palestras. Destaca-se também que apenas uma cooperativa desenvolve projetos que buscam incentivar os jovens a permanecer nas propriedades rurais.

Em relação às ações futuras que as instituições cooperativas poderiam promover para contribuir para a permanência dos jovens no meio rural, as atividades propostas são idealizadas de modo a privilegiar ações econômicas produtivas e que contribuam parcialmente para solucionar os problemas decorrentes da falta de diálogo familiar, o que tem gerado disputas pela tomada de decisão nas propriedades rurais, retardando ou inviabilizando a permanência dos jovens nas unidades de produção.

Por meio desta pesquisa, evidencia-se também que as cooperativas precisam ter um olhar multidisciplinar para promover a sucessão geracional, com base em ações que envolvam a família na discussão do gerenciamento e sucessão geracional do estabelecimento produtivo, aliadas às questões de gênero, entretenimento, renda e trabalho nas propriedades rurais. 
Por fim, considera-se que a promoção da permanência dos jovens no meio rural é de extrema importância para as organizações cooperativas, uma vez que eles fundamentam a própria existência das cooperativas como instituições. Com a saída dos jovens do meio rural, fica a perspectiva de como se dará a renovação das gerações de agricultores no campo e no quadro social das cooperativas agropecuárias. Nesse sentido, as cooperativas devem identificar as ações necessárias de formação e informação para os seus associados, a fim de fomentar a permanência dos jovens, de modo que sigam integrados à instituição, para promover o desenvolvimento do meio rural.

\section{REFERÊNCIAS}

\section{AGÊNCIA DE DESENVOLVIMENTO DO ALTO URUGUAI. Mapa de localização da região Alto Uruguai, Erechim, 2014. Disponível em: <http://www.adaltouruguai.org.br/include/zoom.php?i=basico1\%2F0.8380950011889 29079_mapa3.jpg\&l=Mapa\%20regional>. Acesso em: 05 out 2016.}

ABRAMOVAY, R. et al. Juventude e agricultura familiar: desafios dos novos padrões sucessórios. Brasília, DF: Unesco, 1998.

ABREU, M. A. B. A. Considerações sobre o funcionamento do cooperativismo de crédito no Brasil. In: PALHARES, V. M. A.; PINHO, D. B. (Org). O cooperativismo de crédito no Brasil, do século XX ao século XXI. Santo André: Esetec, 2004.

ALVES, A. G. As cooperativas agropecuárias e o BRDE: história, situação atual e perspectivas. Porto Alegre: BRDE, 2003.

BEDNARÍKOVÁ, Z., BAVOROVÁ, M., PONKINA, E.V., Migration motivation of agriculturally educated rural youth: the case of Russian Siberia. Journal of Rural Studies, v. 45, p. 99-111, 2016. Disponível em: <https://doi.org/10.1016/j.jrurstud.2016.03.006> Acesso em: 02 dez. 2017.

BOURDIEU, P. A dominação masculina. Educação e realidade. Porto Alegre: UFRGS, v. 20, n. 2, jul./dez. 1995.

BRASIL. Lei n. 11.326, de 24 de julho de 2006. Estabelece as diretrizes para a formulação da Política Nacional da Agricultura Familiar e Empreendimentos Familiares Rurais. Diário Oficial da União, Brasília, DF, 24 jul. 2006. Disponível em: <http://www.planalto.gov.br/ccivil_03/_ato2004-2006/2006/lei/l11326.htm> Acesso em: 01 dez. 2017.

Lei no 11.947, de 16 de Junho de 2009. Dispõe sobre o atendimento da alimentação escolar e do Programa Dinheiro Direto na Escola aos alunos da educação básica; altera as Leis nos 10.880, de 9 de junho de 2004, 11.273, de 6 de fevereiro de 2006, 11.507, de 20 de julho de 2007; revoga dispositivos da Medida Provisória no 2.178-36, de 24 de agosto de 2001, e a Lei no 8.913, de 12 de julho de 1994; e dá outras providências. Disponível em: <http://www2.camara.leg.br/legin/fed/lei/2009/lei11947-16-junho-2009-588910-normaatualizada-pl.html>. Acesso em 29 mar. 2018. 
. Lei no 12.512, de 14 de outubro de 2011. Institui o Programa de Apoio à Conservação Ambiental e o Programa de Fomento às Atividades Produtivas Rurais; altera as Leis no 10.696, de 2 de julho de 2003, 10.836, de 9 de janeiro de 2004, e 11.326, de 24 de julho de 2006. 201. Disponível em: <http://www.planalto.gov.br/ccivil_03/_ato2011-2014/2011/Lei/L12512.htm> Acesso em 29 mar. 2018.

BRUMER, A. et al. Juventude rural e divisão do trabalho na unidade de produção familiar. In: CONGRESSO DA ASSOCIAÇÃO INTERNACIONAL DE SOCIOLOGIA RURAL, 10., Rio de Janeiro. Anais... Rio de Janeiro, 2001.

BUARQUE, S. C. Metodologia de planejamento do desenvolvimento local e capitalista. Rio de Janeiro: Civilização Brasileira, 2002.

CARNEIRO, M. J. Herança e gênero entre agricultores rurais. Revista Estudos Feministas, Florianópolis, v. 9, n. 2, p. 22-55, jun./dez. 2001.

Camponeses, agricultores e pluriatividade. Rio de Janeiro: Contracapa Livraria, 1998.

CARNEIRO, M. J.; MALUF, R. S. (Orgs.) Para além da produção: multifuncionalidade e agricultura familiar. Rio de Janeiro: MAUAD, 2003. 230p.

CHAYANOV, A. Teoria das cooperativas camponesas. Porto Alegre: Editora UFRGS, 2017. $296 \mathrm{p}$.

CASTRO, E. G. Juventude rural no Brasil: processos de exclusão e a construção de um ator político. Revista Latino-americana de Ciências Sociais, Infância e Juventude. Manizales: Universidade de Manizales, v. 7, n. 1, jan. 2009.

DEGGERONE, Z. A; LAROQUE, L. F. S.; BARDEN, J. E. Agricultura familiar: o trabalho dos jovens na gestão e reprodução de um modo de vida na região alto Uruguai, Rio Grande do Sul. Boletim Goiano de Geografia, v. 34, n. 2, set. 2014. Disponível em: <https://www.revistas.ufg.br/bgg/article/view/31737>. Acesso em: 15 jul. 2017.

FRANTZ, W.; SCHONARDIE, P. A. As práticas do movimento cooperativo como lugares de educação. In: REUNIÃO ANUAL DA ASSOCIAÇÃO NACIONAL DE PÓSGRADUAÇÃO E PESQUISA EM EDUCAÇÃO, 30., Caxambu. Anais... Caxambu: ANPED, 2007.

GASSON, R.; ERRINGTON, A. The farm family business. Wallingford: Cab International, 1993.

GRIS, V. G. C.; LAGO, S. M. S.; BRANDALISE, L. T. Sucessão na agricultura familiar: produção científica brasileira na área de administração pública e de empresas, ciências contábeis e turismo (2004-2016). Extensão Rural. Santa Maria, v. 24, n.4, p. 7-30, out./dez., 2017. Disponível em: <https://periodicos.ufsm.br/extensaorural/article/view/29816>. Acesso em: 20 abr. 2018. 
GRISA, C.; PORTO, S. I. As contribuições e os desafios para o desenvolvimento rural. In: GRISA, C.; SCHNEIDER, S. (Orgs.). Políticas públicas de desenvolvimento rural no Brasil. Porto Alegre: UFRGS, 2015.

LAUSCHNER, R. A agroindústria cooperativa. In: PINHO, D. B. (Org). Manual de Cooperativismo. São Paulo: CNPq, 1984.

LIMBERGER, E. Cooperativa: empresa socializante. Porto Alegre: Imprensa Livre, 1996.

MORAIS, M; BINOTTO, E; BORGES, J. A. B. Identifying beliefs underlying successors' intention to take over the farm. Land Use Policy, 68, 48-58, 2017. Disponível em: <https://doi.org/10.1016/j.landusepol.2017.07.024>. Acesso em 02 dez. 2017.

MELLO. M., A., et. al. Educação formal e os desafios para a formação de uma nova Geração de agricultores. In: CONGRESSO DA SOCIEDADE BRASILEIRA DE ECONOMIA E SOCIOLOGIA RURAL, 41., Juiz de Fora. Anais... Juiz de Fora: SOBER, 2003.

MENASCHE, R.; SCHMITZ, L. C. Agricultores de origem alemã, trabalho e vida: saberes e práticas em mudança em uma comunidade rural gaúcha. In: MENASCHE, R. (Org). A agricultura familiar à mesa: saberes e práticas da alimentação no Vale do Taquari. Porto Alegre: UFGRS, 2007.

PUTNAM, R. D. Comunidade e democracia: a experiência da Itália moderna. Rio de Janeiro: FGV, 1996.

RECH, D. Cooperativas: uma alternativa de organização popular. Rio de Janeiro: DP\&A, 2000.

SCHNEIDER, J. O cooperativismo e a promoção do desenvolvimento sustentável. Extensão Rural. Santa Maria, n. 8, jan./dez., 2001. Disponível em: $<$ https://periodicos.ufsm.br/extensaorural/article/view/6175/3677>. Acesso em: 20 set. 2017.

.A doutrina do cooperativismo nos tempos atuais. Cadernos Cedop. São Leopoldo: Epagri-Sede, v. 6, n. 12, 1994.

SILVA, W. R. et al. Organizações cooperativas e contexto cultural do espaço público brasileiro: um ensaio teórico sobre processos sociais, universo simbólico e prática social. In: ENCONTRO DA ASSOCIAÇÃO NACIONAL DE PÓS-GRADUAÇÃO E PESQUISA EM ADMINISTRAÇÃO, 30., 2006, Salvador. Anais... Salvador: ANPAD, 2006.

SILVESTRO, M. L. et al. Os impasses sociais da sucessão hereditária na agricultura familiar. Florianópolis: Epagri, 2001.

SPANEVELLO, R. M. A dinâmica sucessória na agricultura familiar. 2008. 236 f. Tese (Doutorado em Desenvolvimento Rural) - Universidade Federal do Rio Grande do Sul, Porto Alegre, RS, 2008. 
SPANEVELLO, R. M. et al. Os impasses no destino do patrimônio entre agricultores familiares sem sucessores no Rio Grande do Sul. In: CONGRESSO DA SOCIEDADE BRASILEIRA DE ECONOMIA, ADMINISTRAÇÃO E SOCIOLOGIA RURAL, 2014, Fortaleza. Anais... Fortaleza: Sociedade Brasileira de Economia, Administração e Sociologia Rural, 2014.

SPANEVELLO, R. M.; LAGO, A. As cooperativas agropecuárias e a sucessão profissional na agricultura familiar. In: CONGRESSO DA SOCIEDADE BRASILEIRA DE ECONOMIA E SOCIOLOGIA RURAL, 45., 2007, Londrina. Anais... Londrina: SOBER, 2007. CD-ROM.

SPANEVELLO, R. M.; DREBES, L. M.; LAGO, A. A influência das ações cooperativistas sobre a reprodução social da agricultura familiar e seus reflexos sobre o desenvolvimento rural. In: CONFERÊNCIA DO DESENVOLVIMENTO, 2., 2012, Brasília. Anais... Brasília: Circuito de Debates Acadêmicos, 2011.

STROPASOLAS, V. L. O valor do casamento na agricultura familiar. Estudos Feministas. Florianópolis, v. 12, n. 1, 2004. Disponível em: <https://periodicos.ufsc.br/index.php/ref/article/view/S0104026X2004000100013/8697>. Acesso em: 23 set. 2017.

WILLIAMSON, O. E. The economics of organization: the transaction cost approach. The American Journal of Sociology, v. 87, n. 3, nov., 1981.

WEISHEIMER, N. Socialização e projetos de jovens agricultores familiares. In: CARNEIRO, Maria José \& CASTRO, Elisa Guaraná de (Orgs.). Juventude rural em perspectiva. Rio de Janeiro: Mauad X, 2007.

WOORTMANN, E.; WOORTMANN, K. O trabalho da terra. Brasília: UNB, 1997. 